\title{
IMPACTS OF JOB PERFORMANCE LEVEL ON NURSES IN PUBLIC SECTOR HOSPITALS
}

\author{
${ }^{1}$ Abdullah Mohammad Al-Homayan, ${ }^{1}$ Faridahwati Mohd Shamsudin, \\ ${ }^{1}$ Chandrakantan Subramaniam and ${ }^{2}$ Rabiul Islam \\ ${ }^{1}$ College of Business, \\ ${ }^{2}$ School of Economics, Finance and Banking, College of Business, \\ University Utara Malaysia, 06010 UUM, Sintok, Kedah, Malaysia
}

Received 2013-07-31, Revised 2013-08-12; Accepted 2013-08-22

\begin{abstract}
Job performance refers to how effective employees are in accomplishing their tasks and responsibilities related to direct patient care. Improving the performance of employees has been a topic of great interest to practitioners as well as researchers. The aim of the study is to analysis the impacts of job performance level on nurses' performance working in public hospitals. In order to achieve the study objective, a survey conducted. Questionnaires distributed to the public sector hospital's manager in Saudi Arabia. The findings of the study turn out to be true; the study will contribute to both theory and practice. Through the present study, the researcher expects the findings to shed light on the research conducted regression to analysis the impacts of job performance level on nurses' in public sector hospitals in Saudi Arabia.
\end{abstract}

Keywords: Job Performance, Nurse, Public Hospital, Interacting Effect

\section{INTRODUCTION}

Improving the performance of employeesa has been a topic of great interest to practitioners as well as researchers (Madsen et al., 2005). But what is job performance and how it is measured so that it reflects the individual's contribution, effort and motivation into the job has been a topic of great debate amongst scholars. Indeed, there is no consensus concerning the definition of the term, job performance, among experts.

Campbell et al. (1970). address eight factors affecting job performance in all occupations: (1) task specific behaviour, (2) non-task specific behaviour, (3) commusnication, (4) effort, (5) personal discipline, (6) assistance to and from colleagues, (7) supervision and leadership and (8) management. Borman and Motowildo (1997) refer task specific behaviour to the activities defined by an employee's job specification and thus vary among employees with different job designations and different roles. On a contrary, non-task specific factors refer to the activities that may be carried out by employees in various roles while at work such as the training of new employees (Campbell et al., 1970). Meanwhile, communication covers all the written and oral methods of transferring information. Besides, an employee's job performance is gauged on the content delivered (Borman and Motowildo, 1997). The effort of an employee in the course of assessing job performance may be looked at on a day to day basis or when the employee is in special circumstances and is a measure of an employee's commitment to his or her work (Campbell et al., 1970). In terms of personal discipline of an employee, it is the history and habits of the employee with certain circumstances (Shuriquie et al., 2008). In jobs where group work is required, the extent to which an employee is ready, available and actually helps out his team and his colleagues when needed is used in the assessment of his job performance (Borman and Motowildo, 1997).

In the context of nursing, job performance refers to how effective employees are in accomplishing their tasks and responsibilities related to direct patient care Corresponding Author: Abdullah Mohammad Al-Homayan, College of Business, University Utara Malaysia, 06010 UUM, Sintok, Kedah, Malaysia 